\title{
DPSIR and Stakeholder Analysis of the Use of Nanosilver
}

\author{
Hansen, Steffen Foss; Baun, Anders
}

\section{Published in:}

NanoEthics

Link to article, DOI:

10.1007/s11569-015-0245-y

Publication date:

2015

Document Version

Peer reviewed version

Link back to DTU Orbit

Citation (APA):

Hansen, S. F., \& Baun, A. (2015). DPSIR and Stakeholder Analysis of the Use of Nanosilver. NanoEthics, 9(3), 297-319. https://doi.org/10.1007/s11569-015-0245-y

\section{General rights}

Copyright and moral rights for the publications made accessible in the public portal are retained by the authors and/or other copyright owners and it is a condition of accessing publications that users recognise and abide by the legal requirements associated with these rights.

- Users may download and print one copy of any publication from the public portal for the purpose of private study or research.

- You may not further distribute the material or use it for any profit-making activity or commercial gain

- You may freely distribute the URL identifying the publication in the public portal

If you believe that this document breaches copyright please contact us providing details, and we will remove access to the work immediately and investigate your claim 
This is a Post Print of the article published online 29.10.2015 and printed October 2015 in Nanoethics, Vol. 9. The publishers' version is available at the permanent link: DOI 10.1007/s11569-015-0245-y

\title{
DPSIR and Stakeholder Analysis of the Use of Nanosilver
}

\begin{abstract}
First concerns about the use of nanosilver were raised almost a decade ago, but assessing the risks has been extremely challenging scientifically, and regulation to protect environmental and human health remains controversial. In order to understand the known risks and issues associated with the use of nanosilver, we carried out a DPSIR analysis and analysed drivers, pressures, state, impacts and potential policy responses. We found that most concerns relate to the potential development of multi-resistant bacteria and the environmental impacts of nanosilver. From the DPSIR analysis, we found that new (separate) legislation for nanomaterials in general and nanosilver-specific changes in the current European chemical, biocide and medical legislation were the optimal policy responses, along with limiting the overall use of nanosilver. In order to qualify the identified potential policy responses, we carried out a stakeholder analysis, in order to explore possibilities for reaching consensus among stakeholders. Through the stakeholder analysis, the interests, views, power and influence of the identified stakeholders were mapped. Overall, the policy options identified in the DPSIR analysis were deemed not to be implementable, as industry and NGOs seem to have fundamentally conflicting views and interests. The use of the combination of DPSIR and stakeholder analysis proved valuable for use in cases of complexity, as they compensate for each other's limitations and open up for a discussion what can be done to reduce risks.
\end{abstract}

Keywords: Nanosilver, DPSIR, stakeholder analysis, regulation, ethics 


\section{Introduction}

The use of nanosilver has increased dramatically in recent years, and about $20 \%$ of all proclaimed nanoproducts now contain nanosilver [1]. A lot of concern has been raised about its use, especially in regard to its widespread prevalence in everyday consumer products, and it is reportedly one of the most widely used nanomaterials in these products today [1].

A lot of the discussions about the risks of nanosilver have circled around whether it is toxic to humans and the environment and, if so, then whether it is more toxic than bulk silver [2-5]. The preferred scientific approach used to make arguments for and against regulation has been chemical risk assessment [6], which consists of four steps, namely hazard assessment, dose-response assessment, exposure assessment and risk characterisation. In Europe, the purpose of chemical environmental risk assessment is to determine whether the ratio between the predicted environmental concentration (PEC) and the predicted no effect concentration (PNEC) is below or above 1. The PNEC is determined scientifically via laboratory tests on a base set of organisms (daphnia, algae and fish) under very standardised conditions, whereas the PEC is most often determined via the use of mathematical equations and models. The assumption is, if the PEC/PNEC ratio is below 1, than there is no risk to the environment and risk management is not needed, whereas, if the ratio is above 1 , risk-reducing measures are required $[7,8]$. Risk assessment has been criticised in the past for being very reactive and focusing on studying the risk in question in ever and ever greater detail instead of being proactive and focusing on understanding what can be done in order to reduce the risks [9-11]. 
According to cultural theory, stakeholders can be categorized into four overall groups depending on how the perceive nature and this explains seemingly unresolvable disputes concerning human and physical nature. The four categories are:

1. Individualists, who perceive man as inherently self-seeking and nature as benign and resilient and able to recover from any exploitation;

2. Egalitarians, who perceive man as caring and sharing and nature as fragile, intricately interconnected and ephemeral;

3. Hierarchists, who perceives nature as being stable until pushed beyond discoverable limits. By hierarchists, man is perceived to be deeply flawed, but redeemable by firm, long lasting, and trustworthy institutions;

4. Fatalists perceive nature as meaningless and man as untrustworthy and that there is no possibility of effecting change for the better [12].

Chemical risk assessment is based on a hierarchist point of view of nature as being stable until pushed beyond discoverable limits and that nature is able to hide a given response when exposed to stress within certain boundaries $[12,13]$. This is reflected in the belief that all adverse impacts to, for instance, air, water and soil organisms can be determined individually, in order to verify the overall adverse environmental impact of a given chemical, while the environment will be protected as long as the PEC/PNEC ratio is less than 1. Utilitarianism is the moral theory that might be most closely related to the hierarchist point of view of nature and provides the foundation of risk assessment. The question is, what would happen if we used tools other than risk assessment that had a different focus and a different cultural and ethical foundation? Would we, for instance, be able to become more reactive and more focused on understanding what can be done, in order to reduce the risks in question? 
Furthermore, what could we learn about the regulation of nanomaterials, if we used a decision-support tool such as stakeholder analysis based on a libertarian perspective? More specifically, it would be a libertarian perspective that opposes regulation and advocates the maximum freedom of individual action compatible with equal freedom for all $[14,15]$ and which again is closely related to the individualist viewpoint of nature that tends to perceive nature as resilient in the sense that it will vacillate from its baseline state when exposed to stress, but it can return to the baseline state if the stress is lessened or removed [12]. Similarly, what could we learn if we used a tool such as drivers, pressures, state, impact, responses (DPSIR) analysis that is inspired by land ethics?

In order to elucidate on these questions, we undertook a DPSIR analysis and analysed drivers, pressures, state, impacts and potential policy responses, with the purpose of understanding and mapping the known risks and uncertainties associated with the use and regulation of nanosilver. In order to subsequently qualify the identified potential policy responses, we carried out a stakeholder analysis, in order to explore possibilities for reaching consensus among stakeholders in regard to the regulation of nanosilver.

\section{DPSIR analysis of the use of nanosilver}

DPSIR stands for driving forces (D), pressures (P), state (S), impacts (I) and responses (R). Driving forces are normally defined as "needs" that society and others are trying to meet, but it could also include factors that motivate different societal actors to engage in various activities. Individual primary needs, for instance, could be shelter, food and water, whereas secondary needs could include mobility, entertainment and culture. On a broader societal scale, needs could include jobs, consumption, etc. $[16,17]$. 
Pressures (P) are defined as the results of meeting a need, and they can be divided into three main types: 1) excessive use of environmental resources, 2) changes in land use and 3) emissions into the air, water and soil. The state (S) is supposed to be a reflection of the current physical, chemical or biological state of the environment as well as human health and welfare. It can include a description of functioning ecosystems, locally and globally, the quality of various environmental compartments (air, water, soil) and/or human well-being and health. Whereas the state provides a snapshot of the present situation, impacts (I) focus on future changes in the state that could be the result of driving forces. Finally, responses (R) in DPSIR are defined as actions that policymakers, society, stakeholders and others can take to address an undesired impact. An important aspect of DPSIR analysis is related to how the various elements (D, P, S, I and R) are linked when it comes to a specific issue. For instance, the relationship between $\mathrm{D}$ and $\mathrm{P}$ might be linked by economic activities in one set of circumstances and by social behaviour patterns under a different set of circumstances [16].

DPSIR analysis has now been used in more than 20 studies covering a range of issues such as water management, degradation of land, climate change, marine habitat and sustainable development [17], but this is the first time that it has been applied on nanomaterials in general and nanosilver specifically.

The roots of DPSIR and its ethical foundation can be traced back to the stress-response framework developed by Canada’s national statistical agency, known as Statistics Canada, back in the late 1970s [18]. Statistics Canada needed to 'evaluat[e] landscape change', which required integrating the social and natural sciences. Social sciences contribute to articulate societal values that govern landscape changes, while natural science contributes to understanding the biophysical processes that influence human activities and result in ecological changes. 
'Building upon Aldo Leopold's criteria for landscape health... a framework is developed for indicators of landscape health and integrity' Rapport et al. [18] state in their landmark paper from 1998. According to Rapport et al. [18], Leopold argued that the boundaries of the community should be enlarged to include the land, and we have to change from 'conquerors of the land community to plain member and citizen of it'. As a general guide, Leopold argued that 'A thing is right when it tends to preserve the integrity, stability and beauty of the biotic community. It is wrong when it tends otherwise'. In their interpretation of Leopold, Rapport et al. defined landscape health as a condition under which 'the land could be humanly occupied without rendering it dysfunctional'. Human modifications to the landscape bring compromises essential to ecological functions that are necessary to sustain landscape components and processes. Humans are "part of" and not "apart from" the landscape, and hence the degree to which the landscape satisfies human needs and aspirations must be prominent in any assessment of landscape health [18].

In the early 1990s, the Organisation for Economic Co-operation and Development (OECD) looked for environmental performance indicators and was inspired by the stress-response framework developed by Statistics Canada. Stress was reformulated to "state”, which was limited to mean concentrations of substances and the distribution of species. The OECD furthermore removed the ecosystem response and rephrased "response” to mean societal response only, thereby making the concept more suitable for the approach used by the OECD [19]. Pressures were finally added to the framework as well, and they were defined as 'all releases or abstractions by human activities of substances, radiation and other physical disturbances, and species in or from the environment'.

In 1995, the European Environment Agency (EEA) added drivers (D) and impacts (I) to the framework, in an effort to find and develop an effective way to communicate sound, independent information on the environment to busy policymakers. DPSIR has subsequently been used by the EEA to structure their five annual state-of-the-environment reports [16]. 


\subsection{Driving forces when it comes to nanotechnology and nanosilver}

Nanosilver has antibacterial properties, which is the dominating driver for using it in medical applications as well as in consumer products. The antibacterial properties of nanosilver have been exploited in a very diverse set of products and applications, including dietary supplements, personal care products, powdered colours, varnish, textile, paper, interior and exterior paints, printing colours, water and air purification, polymer-based products and foils for antibacterial protection in washing machines, kitchenware and food storage products [1].

Some drivers are specific to nanosilver, such as antibacterial properties, but others are broader in the field of nanotechnology. Nanotechnology research \& development has been on the agenda in the EU for more than two decades [20]. In 2004, the European Commission adopted the Communication “Towards a European Strategy for Nanotechnology” [20], which sought to 'bring the discussion on nanosciences and nanotechnologies to an institutional level and proposes an integrated and responsible approach for Europe', but it is clear from the outset that the main focus was on the exploitation of nanotechnology for the development of products and processes promoting innovation, economic growth and the creation of jobs. For instance, it is stated that 'European excellence in nanosciences must finally be translated into commercially viable products and processes' and that 'it is crucial, however, that a favourable environment for innovation is created, in particular, for small and medium sized enterprises (SMEs)', while there must be '...increase[d] investment and coordination of $\mathrm{R} \& \mathrm{D}$ to reinforce the industrial exploitation of nanotechnologies whilst maintaining scientific excellence and competition’ [20].

In 2005, the European Commission adopted the Communication "Nanosciences and nanotechnologies: an Action Plan for Europe 2005-2009”, which aimed at defining a series of articulated and interconnected actions for the immediate implementation of a safe, integrated and 
responsible approach to nanosciences and nanotechnologies ( $\& \mathrm{~N})$. Again, it is apparent from the action plan that the focus of $\mathrm{R} \& \mathrm{D}$ on nanoscience and nanotechnology was to create useful, wealthgenerating products in line with the actions for growth and jobs [21].

Through its framework programmes, institutions of the European Union have put a more than 4.9 billion $€$ into the development of nanotechnologies since 2002, in order to promote the use and commercialisation of this specific technology [22], while private R\&D funding in this respect has been estimated to be close to 2 billion $€[21]$.

Nanosilver is not specifically mentioned in the Communications, but some of the applications and areas of potential growth are relevant for nanosilver, such as medical applications and food, water and environmental research [20].

\subsection{Pressures related to the use of nanosilver}

The pressures that the increased use of nanosilver might put on the human health and the environment have been subject to multiple reviews [2]. In 2012, the European Commission's Scientific Committee on Newly Identified Health Risks (SCENIHR) was asked to assess 1) whether the use of nanosilver could result in additional risks compared to more traditional uses of silver, in particular in medical care and in consumer products, and 2) whether the use of nanosilver to control bacterial growth could result in the resistance of micro-organisms. The committee concluded that the widespread and increasing use of silver-containing products means that both consumers and the environment are exposed to new sources of silver and that the additional effects caused by this widespread and potentially long-term use of silver nanoparticles cannot be ruled out [5].

Regarding the hazard associated with the dissemination of the resistance mechanism following the use of silver nanoparticles, no studies are available at this current moment, thereby representing a serious gap in the knowledge. Since other nanoparticles have been shown to increase 
substantially horizontal gene transfer between bacteria - which is extremely relevant for developing resistance - the potential of silver nanoparticles to induce similar effects should be given particular attention, according to SCENIHR, as more data are needed to understand better bacterial responses to ionic silver and silver nanoparticle exposure [5].

When it comes to the adverse effect of nanosilver in humans, a permanent bluish-grey discoloration of the skin or eyes, known as argyria or argyrosis, has been reported after chronic, albeit very high and repeated, oral or respiratory exposure to silver. This discoloration is undesirable; however, it is not life-threatening. Many nanosilver applications involve direct exposure of the substance to humans, and it has been shown that silver from nanoparticles can enter the body either orally or via inhalation. It has furthermore been found that silver from nanoparticles is absorbed and distributed to various organs in the human body, such as the liver, olfactory bulb, lungs, skin, brain, kidneys and testes [23, 24]. It remains unclear, however, in what form it is transmitted and accumulated in the body, as silver can be present as ion, as particles or as complexes [24]. In laboratory studies, a number of studies have reported that nanosilver causes inflammation and slight liver damage in mice after oral exposure [24, 26], while inflammatory responses and alterations in the lung function of rats have been observed after prolonged exposure to nanosilver particles via inhalation [23].

When it comes to the environment, silver is well-known to be ecotoxic, and it is also known that toxicity is highly dependent on the form and speciation of the metal. For instance, for ionic silver, it is known that speciation in aqueous media determines bioavailability and toxicity. For nanosilver, half-maximum concentrations (also termed $\mathrm{EC}_{50}$-values) as low as $4 \mu \mathrm{g} / \mathrm{L}$ have been found for freshwater algae, and values far below $1 \mathrm{mg} / \mathrm{L}$ have been reported for crustaceans [2731]. EC50 is the maximum concentration to induce an adverse effect in $50 \%$ of the test population. Inhibiting nitrifying bacteria is important as well as the proper functioning of wastewater treatment 
plants is critically depended on these bacteria and nanosilver has been reported to affect nitrifying bacteria at concentrations below $1 \mathrm{mg} / \mathrm{L}$ [32].

It is important to note that the release of dissolved silver has been suggested to be the main cause of toxicity in many studies, when it comes to humans, in the environment and in hygienic applications, on the one hand, whereas an increasing number of studies, on the other hand, find that this release cannot account alone for the toxic effects observed [5]. Therefore, it remains uncertain as to whether silver nanoparticles are more toxic than their bulk counterpart or ionic silver [3].

\subsection{State}

It is hard to evaluate the state of human health, well-being and the environment when it comes to nanosilver specifically, as it continues to be a significant technical and scientific challenge to measure the impact of its increased release into the environment or even measuring it in the environment itself.

In general, however, it can be said that environmental media for which exposure to nanosilver is to be expected are already under pressure. In their state-of-the-environment report from 2015, the European Environment Agency (EEA) elucidates how Europe is far from meeting its water policy objectives, aimed at ensuring healthy aquatic ecosystems. According to the EEA, there has been a modest improvement compared to 2009 when it comes to the number of surface water bodies that enjoy a good or high ecological status. However, rivers and transitional waters seem to be worse off than lakes and coastal waters, and the ecological status of surface water bodies is under a lot of pressure in central and north-western Europe in areas that are home to intensive agricultural practices and high population densities [33]. The chemical status of rivers and lakes is furthermore considered to be poor in around $10 \%$ of cases, due to contamination by polycyclic aromatic hydrocarbons and heavy metals. For groundwater, 25\% has a poor status, due to pollution 
by nitrate. It should be noted that the chemical status of $40 \%$ of Europe's surface waters remains unknown [33].

The development of bacterial resistance is also a well-known problem that seems to be on the rise, as antimicrobial resistance is present in all parts of the world and new resistance mechanisms have emerged and spread globally. According to the World Health Organization [34], antimicrobial resistance threatens the effective treatment of infections by bacteria, parasites, viruses and fungi. For instance, there were about 450,000 new cases of multidrug-resistant tuberculosis in 2012 across 92 countries, resistance to earlier-generation antimalarial drugs has become widespread in most malaria-endemic countries, high proportions of antibiotic resistance in bacteria cause common infections such as urinary tract infections, pneumonia and bloodstream infections in all regions of the world, and gonorrhoea may soon become untreatable due to treatment failures as a result of drug resistance. Finally, highly resistant bacteria such as methicillin-resistant Staphylococcus aureus or multidrug-resistant Gram-negative, are causing a high percentage of hospital-acquired infections [34].

\subsection{Impact}

Gaps in the knowledge make it impossible to assess the potential human impacts of the increased use of nanosilver at this point in time. Key gaps relate to current and future environmental and human exposure to nanosilver, human and environmental toxicity and, finally, the development of resistance as a consequence of continued application.

The availability of reliable production data, use information and exposure measurements of nanosilver in various applications in mass/volume hampers reliable exposure assessment. This includes the identification of nanosilver or differentiation between different coatings [25, 35]. 
When it comes to assessing the impact of nanosilver on human health, there is a need for more data, information and research on, for instance, inhalation toxicity after repetitive exposure to concentrations relevant for the workplace, in order to detect local and possible systemic effects. In addition, we require dermal uptake studies, to analyse and detect local/systemic dermal effects, as well as in vitro and in vivo investigations, to decide on primary and/or secondary genotoxic effects, carcinogenicity and reproductive toxicity. Toxicokinetics, with appropriate detection methods, is furthermore required in order to understand the absorption of nanosilver via different exposure routes (inhalation, dermal and oral, when relevant) and metabolism/elimination via alveolar macrophages, Kupffer cells or other pathways [5, 36]. Overall, the numbers of well-controlled studies on the potential toxicities of nanosilver are limited, and in an extensive review of risk assessments, Wijnhoven et al. [37] concluded that this fact - along with the limited knowledge about kinetics of nanosilver - makes it impossible to complete a human risk assessment.

Similarly, it is hard to predict what the actual impact of the continued release of the metal would be, as nanosilver goes through several transformations once released into the environment. These transformations are not well-understood at this point in time, but they include aggregation and agglomeration as well as dissolution and subsequent speciation into, for example, silver chloride and silver sulphide. Chemical species and the physical, chemical and biological conditions that are present determine the bioavailability and toxicity of silver once released into the environment, which again makes it hard to determine the potential impacts of its continued use [2, 3, 5].

Although it is hard to assess its actual effects, a number of expert committees have warned against nanosilver. For instance, in 2009, Aitken et al. [38] stated that there is '...indicative evidence of the harm of silver nanoparticles at low concentrations on aquatic invertebrates, which suggests that the environmental release of silver nanoparticles will be detrimental for the 
environment and that any industry/institute using silver nanoparticles should consider taking the necessary steps to reduce or eliminate the potential exposure of the environment to these nanoparticles'.

Regarding the hazard associated with the development of resistance following continued exposure to nanosilver, no documentation is available at the moment, and this has been identified as a serious gap in the knowledge [5]. Since the mechanisms resulting in silver nanoparticles resistance are furthermore not well-understood, it has not been possible for SCENIHR [5] to estimate whether or not the resistance of microorganisms will increase and spread due to more widespread use of silver nanoparticles in products. However, should this be the case, the consequences could be quite grim, as patients with infections caused by drug-resistant bacteria are known to be at an increased risk of worse clinical outcomes and death, thus consuming more healthcare resources [34].

\subsection{Responses}

A range of different responses has been suggested when it comes to the regulation of nanomaterials in general and nanosilver specifically.

In 2012, the Biocidal Products Regulation became the first piece of legislation to implement the European Commission's definition of a nanomaterial, and it was also the first to require a separate dossier with all data requirements to be prepared for nanoforms and to require a dedicated risk assessment when the nanoform of a substance is used. These requirements also apply to nanosilver when used as a biocidal active substance, biocidal product or in treated articles [39].

No responses have been made specifically to the general production and application of nanosilver. In their Second Regulatory Review on Nanomaterials from 2012, the European Commission [40] argued that European chemical legislation, known as REACH (Registration, 
Evaluation, Authorisation and Restriction of Chemicals), '...sets the best possible framework for the risk management of nanomaterials when they occur as substances or mixtures but more specific requirements for nanomaterials within the framework have proven necessary'. Specifically, the European Commission envisioned modifications in some of the REACH Annexes, which currently specify, for instance, the technical details of how to carry out a chemical safety assessment, provide information on what to include in a safety data sheet and detail criteria for the identification of persistent, bioaccumulative and toxic (PBT) substances [40].

During the course of June-September 2013, the European Commission [41] held a stakeholder consultation and public consultation relating to the REACH Annexes on nanomaterials, asking respondents to evaluate six different policy options or responses that could be adopted:

- Policy option 1: This potential response is termed the "base line option” and assumes that the current situation under REACH is maintained and that no new policy actions are taken;

- Policy option 2: This response acknowledges that the quality of the information provided by industry in their chemical safety assessment dossiers falls below the baseline obligations and therefore would introduce changes to certain REACH Annex provisions to clarify what companies are expected to do in accordance with their registration obligations, e.g. clarification of requirements for nanoform-specific information in a number of specific endpoint sections, as well as clarification on how data are to be reported.

- Policy option 3: The third potential response that respondents were asked to evaluate relied on non-legally binding measures only, in order to provide more clarity. These measures would include updates on guidance, FAQs, etc. and basically all other sorts 
of actions that can take place without changing any legal provisions and which are not binding to those to whom they are addressed [41].

- Policy option 4: The fourth response entails full implementation of policy option 2 in addition to the implementation of scientific or technical obligations recommended to demonstrate safe use in cases where the existing information requirements in REACH are not tailored to nanomaterials, or where specific considerations are required for nanomaterials. Measures that could be implemented under this option include revised or additional endpoints for nanomaterials (inhalation exposure route for acute toxicity, repeated dose toxicity studies and a non-bacterial gene mutation study (in vitro)), the exclusion of waiving on the basis of insolubility or lack of short-term toxicity and a priority procedure for testing soil and sediment organisms.

- Policy option 5: Policy option 5 focuses on enhancing the competitiveness and innovation of companies, by providing greater specificity to core implementation issues and by reducing the economic burden involved in complying with REACH. Measures that could be envisioned included tailored information requirements for nanomaterials placed on the market, the clarification of regulatory provisions and even the reduction of certain information requirements [41].

- Policy option 6: The final potential response assumes full implementation of option 2 and option 4 and places additional emphasis on the generation of targeted information regarding the influence of particle- and nanomaterial-specific properties on risk. Information generated should also facilitate the development of category approaches with all associated impacts; the physico-chemical characterisation of different forms covered by a given registration the dossier would be diligently pursued [41]. 
In contrast to the European Commission, a number of environmental and consumer NGOs have called for a so-called "nano-patch" when it comes to nanomaterials in general. Specifically, Center for International Environmental Law (CIEL) [42] and a range of European partners (including ClientEarth and the European Environmental Bureau) published a position paper on the regulation of nanomaterials, calling for the European Commission to come forward with concrete proposals for a comprehensive revision of the existing legal framework addressing the potential risks of nanomaterials. CIEL and its partners argued that:

- Nanomaterials should undergo a thorough risk assessment of the potential risks deriving from their novel properties;

- Industry should be required to submit comprehensive substance identity and characterisation data for all nanomaterials on the market;

- All nanomaterials on the market produced in amounts of over $10 \mathrm{~kg} /$ year should be registered before 2018;

- All registration dossiers of nanomaterials must include a chemical safety assessment similar to substances classified as carcinogenic, mutagenic or reprotoxic (CMRs);

- Nanomaterials should be thoroughly evaluated for compliance, and these tests should be carried out without delay;

- Information should be disseminated through the establishment of a publicly accessible nanomaterial inventory at European level;

- Specific nano-labelling or declaration requirements must be established for all nanocontaining products (detergents, aerosols, sprays, paints, medical devices, etc.) and

- Nanomaterials on the market without a meaningful minimum set of hazard and risk data should be denied market access [42]. 


\section{Stakeholder analysis in relation to nanosilver in the EU}

Stakeholder analysis is normally said to entail four overall steps: 1. stakeholder identification, 2. mapping of stakeholder interests, 3. evaluation of stakeholders' importance and influence and 4. the development of a stakeholder strategy plan [43, 44]. In the following, we will complete the first three steps of stakeholder analysis when it comes to nanosilver in the EU, while any future potential strategy will be discussed in the overall discussion.

Stakeholders can be identified by asking: What people/groups/institutions have an interest? Who are the potential beneficiaries? Who might be adversely affected? Who are constrained by the initiative? And who might affect and has the power to influence the initiative?

Once the various stakeholders have been identified, their interests have to be mapped to the best extent possible. Stakeholders have very different interests, motives and expectations, and whereas some of these are well-defined and openly expressed, others can be hidden and hard to identify. When trying to identify stakeholders, the research questions that one should attempt to answer include: What are the stakeholders' expectations? What benefits are there likely to be for the stakeholders? What resources will the stakeholders wish to commit (or avoid committing)? What other interests do the stakeholders have which may conflict with the project? And how do the stakeholders regard their fellow stakeholders?

Evaluating the stakeholders' importance and influence is the third step in a stakeholder analysis, and is it essential for the formulation of a stakeholder strategy plan as well as for future participatory decision-making. Here we define “importance” and "influence” as the ability of a stakeholder to affect the success or failure of an initiative and to affect it implementation due to his or her strength or force. Specifically, we have evaluated the identified stakeholders in regard to their political legitimacy and legal mandate and 2) available resources and staff [43]. 
The roots of the stakeholder analysis can be traced back to Freeman [45], who introduced the term "stakeholder approach" as a management tool to address the problems of 1) understanding and managing a business in a $21^{\text {st }}$-century world and 2) thinking about questions relating to ethics, responsibility and sustainability in line with the usual economic view of capitalism [45].

The central idea behind the stakeholder approach is that an organisation's success is dependent on how well it manages its relationships with key stakeholder groups, e.g. customers, employees, suppliers, communities, financiers and others, that can affect the realisation of its purpose. The ethical foundation of the stakeholder analysis has been subject to a good deal of discussion. In a response to the claim that it is based on a socialist viewpoint, Freeman and Phillips [46] argued that libertarian conditions apply instead. One line of arguments provided by Freeman and Phillips [46] goes along the lines that due to bounded rationality and uncertainty, we 'cannot trust that a governmental solution will continue to be optimal, even though it might look more favorable than one that deals directly with key stakeholders'.

\subsection{Stakeholder identification}

In this stakeholder analysis, we identified relevant stakeholders by scrutinising articles published in Chemical Watch on "nanosilver" and "silver" since 2010. Chemical Watch is an online journal established in 2007 which gathers the latest developments on chemical legislation around the world and summarises them for its subscribers to read [47, 48]. As of April, 2015 a total of 85 Chemical Watch briefings and articles had been published.

The identified stakeholders can be divided into five overall categories: 1) European institutions (such as the European Commission and the European Parliament); 2) member states of the European Union, e.g. Sweden, the Netherlands; 3) businesses and branch organisations such as RAS Materials, HeiQ Materials AG, CEFIC and NIA; 4) environmental and consumer NGOs, e.g. 
CIEL, EEB and BEUC, and 5) the scientific community, including expert groups from the European Commission as well as individual academic scientists.

\subsection{Mapping of stakeholder interests}

In this study, we used three different sources of information to map the interests of the identified stakeholders. First, we gathered information on their self-proclaimed aims and missions. Second, we gathered information about their perspectives on the regulation of nanosilver specifically, and third, we gathered information on their perspectives on the regulation of nanomaterials in general. It should be noted that some of identified stakeholders were involved in the European Commission's public consultation regarding the REACH Annexes on Nanomaterials and have made their evaluation of the six different policy options publicly known, whereas other have not.

\subsubsection{European institutions}

\section{The European Commission}

As outlined above, the European Commission [40] is of the belief that REACH ' ...sets the best possible framework for the risk management of nanomaterials...' while also envisioning modifications in some of the REACH Annexes. A public consultation was organised by the European Commission in 2013, and after the consultation ended, the Commission was supposed to have reviewed responses with the aim of submitting draft legal measures by the end of 2013 [49]. As of January 2015, the European Commission is still working on drafting changes to these annexes, and a related impact assessment is in its final stages [50].

The European Commission is divided into several departments and services, also known as directorate-generals (DGs). In the Commission, the European Commission's DG for Internal 
Market, Industry, Entrepreneurship and SMEs (GROW) (formerly known as DG Enterprise) and DG Environment are jointly responsible for EU chemicals regulation [51, 52].

DG GROW is the European Commission service responsible for, among other, completing the internal market for goods and services and 'helping turn the EU into a smart, sustainable, and inclusive economy by implementing the industrial and sectorial policies of EU's growth strategy known as the Europe 2020 initiative'. When it comes to priorities, DG GROW work in order to ensure an open internal market for goods and services in the EU, strengthen the industrial base in Europe, provide sector-specific and business-friendly policies and promote industrial innovation to generate new sources of growth [51].

The objective of DG Environment is to protect, preserve and improve the environment for present and future generations [52]. As part of the Commission, they do so by proposing policies and legislation that protect natural habitats, keep air and water clean, ensure proper waste disposal, improve knowledge about toxic chemicals and help businesses move towards a sustainable economy [53].

When it comes to the "nano-patch" suggested by CIEL, the EEB and other environmental and consumer NGOs, the European Commission has been reported to disagree about the best way forward. DG Environment has argued that it would probably take at least five years to draft such a regulation, considering that it would have to be discussed by the EU's political institutions and then come into force and that 'we don't have that luxury, so the only choice we have is to make REACH work [for nanomaterials]'. Representatives from DG Environment have furthermore argued that REACH already requires a huge amount of information to assess adequately the risks of nanomaterials, but dossiers submitted by industry have failed to include it [54].

In contrast, DG GROW (when it was called DG Enterprise) issued a separate statement regarding the ability of REACH to regulate nanomaterials, arguing explicitly that: 
- It is not appropriate to change the registration rules and the rules for when a chemical safety assessment is required under REACH;

- Nanomaterials do not differ substantially from other chemical substances with respect to their toxicity and

- The highest-volume substances have already been registered under REACH [55].

This is not the first time that DG Environment and DG GROW have been reported to disagree substantially over issues related to the regulation of nanomaterials. Back in 2011, it was reported that the directorates disagreed so much over the definition of nanomaterials that it caused increasing frustration among member states. The NGO CIEL commented that such internal divisions and 'a lack of political will' were stopping the EU from playing a leadership role in relation to nanomaterials [56].

\section{The European Parliament}

Along with the Council of the European Union, the European Parliament is one of the EU's two law-making institutions. EU voters directly elect members every five years, and the European Parliament has steadily been gaining more and more power over recent decades. It has three main roles, including debating and passing European laws and scrutinising particularly the European Commission. Furthermore, together with the Council, the Parliament adopts or amends proposals made by the Commission. When it comes to nanomaterials, the European Parliament has been very proactive and instrumental in the implementation of labelling requirements in cosmetics and biocides, as well as the implementation of nano-specific testing requirements when it comes to biocides. In regard to REACH, the European Parliament's view is that nanomaterials should be treated as new substances and require all applicable safety testing and mandatory labelling [57]. 


\section{The European Chemical Agency}

The European Chemical Agency (ECHA) is the main body responsible for the implementation of European chemicals legislation, REACH for the benefit of human health and the environment as well as for innovation and competitiveness. ECHA engages in numerous activities related to providing assistance to companies on how they can comply with REACH, by providing information on chemicals, addressing chemicals of concern and, finally, advancing the safe use of chemicals [58]. When it comes to nanomaterials, ECHA has stated that they are convinced that there are many more nanomaterials on the market that are not correctly registered, and it has placed on public record its acknowledgement that there are many data gaps and measurement hurdles and that regulation should not wait - 'we need to run before we can walk' [59]. ECHA's executive director, Geert Dancet, has also asked for the European Commission to move faster to clarify the REACH registration information requirements for nanomaterials, so the agency can ensure the substances are scrutinised properly [50].

When the annexes covering REACH information requirements have been changed to clarify the requirements for nanomaterials, ECHA will need time to update guidance so companies understand what they need to do, the agency's executive director explained. In addition, 'as we want to freeze our guidance two years before the [2018 deadline for] registration, the clock is already ticking'. ECHA updated some of its guidance on information requirements and chemical safety assessments back in 2012, and these amendments took into account the conclusions and recommendations of the REACH implementation project on nanomaterials and information requirements (RIP-oN 2) and on chemical safety assessment (RIP-oN 3) [54]. ECHA has also asked for clarification on whether the registration requirements for substances on the EU market in low amounts will be changed, as ‘very toxic chemicals are often sold in small amounts’ [50]. 


\subsubsection{Member States of the European Union}

\section{The Netherlands}

Under REACH, the Dutch are especially important, as they are the REACH competent authorities in charge of the substance evaluation of silver [54,60]. According to Chemical Watch, the Netherlands has been pressing for EU-wide legislation and a regulatory solution [54]. Back in 2012, the Dutch Environment Ministry held a conference attended by a range of stakeholders, and according to the adopted conclusions, there was "broad" support for the Commission to take urgent action on regulating the production and use of nanomaterials. The conclusions furthermore argued that the REACH annexes and guidance should be amended, while also recognising that this will not solve issues such as whether tonnage limit values and exposure assessments are appropriate, or whether "nano-patch legislation" is desirable that would be coherent, not only with REACH, but also with other relevant legislation.

The Dutch have also been asking other member states for their support in sending a letter to the European Commission, inviting them to, among other things:

- Amend the REACH annexes and guidance to enable their application to nanomaterials

- Consider putting in place legislation for the registration or market surveillance of nanomaterials or products containing nanomaterials

- Review the current tonnage limit values for nanomaterials within REACH [54].

\section{Sweden and the Swedish Chemicals Agency}

The Swedish Chemicals Agency (KEMI) is the competent authority conducting an assessment of the use of nanosilver as a biocidal active ingredient under the EU's biocidal product regulation's review programme. Therefore, KEMI is often referred to in discussions about nanosilver. According to KEMI, their work is progressing slowly, and it is not possible for them to say whether 
there are sufficient data to carry out a risk assessment on the nanoforms of silver, as the data submitted by industry follow the usual data requirements for bulk substances. It is furthermore unclear whether these are really suitable for the nanoforms, and they argue that there is practically no guidance on how to deal with uses of biocides in consumer articles or how to carry out risk assessments in this regard [61].

\section{German Federal Institute for Risk Assessment}

The German Federal Institute for Risk Assessment (BfR) is an independent agency operating under the German Federal Ministry of Food and Agriculture, and it is tasked with the scientific risk assessment of food, feed, substances and products as the basis for consumer health protection [62]. The BfR has repetitively called for manufacturers not to use nanosilver, as lack of data on the substance prohibits the effective assessment of health risks. As such, BfR has advised against the broad use of nanosilver in consumer products until potential health risks can be ruled out [63, 64].

\subsubsection{Businesses and their branch organisations}

\section{CEFIC}

CEFIC is the trade association for the European chemical industry, and it is actively involved in EU legislative processes when it comes to chemicals, by providing testimonies on legislation or opinion papers and fact sheets and working 'to protect the environment, public health, and the competitiveness of European economy, promoting healthy and safe chemistry for the future’ [65].

When it comes to nanomaterials in general, the European chemical industry believes that the existing risk assessment paradigm and regulatory framework provide a solid basis for ensuring that nanomaterials are produced, used and disposed of in a safe and sustainable way. CEFIC furthermore argues that nanomaterials are chemical substances, REACH regulations have been put 
in place to ensure safety and that REACH guidance is applicable to nanomaterials after recent amendments integrated into ECHA guidance [66].

When it comes to nanosilver specifically, CEFIC argues that although most people acknowledge the benefits that nanomaterials bring, they still nonetheless tend to perceive nanosilver as being dangerous. According to CEFIC, the current approaches for testing and assessing traditional chemicals, established by the OECD, are generally appropriate for assessing the safety of nanomaterials, which means, according to CEFIC, that there are no unique safety issues associated with nanomaterials and that they just need to be assessed in the same way as other materials [67].

In the public consultation process, in which the European Commission asked respondents to evaluate six different policy options in regard to pontifical revisions to the REACH Annexes on nanomaterials, CEFIC backed option five, which would allow for the reduction of certain information requirements, the maximisation of non-testing methods and exposure categorisation and openness to flexible solutions.

CEFIC argues that the lack of validated and certified measurement techniques is hampering efforts to better address nanomaterials in REACH, while regulatory control of nanomaterials must 'include the increasing understanding of leading scientists that a nano-specific toxicity does not exist and that conventional data are useful and relevant to the evaluation of nanoparticle hazard’ [49].

CEFIC furthermore argues that option six, preferred by, for instance, the European Environmental Bureau, overestimates the relevance of nano size for risk assessment without any scientific justification, as no nano-specific toxicity has been demonstrated to this date, and requiring data for non-relevant exposure conditions and endpoints would significantly increase registration costs, without any commensurate improvement in safety [49]. 


\section{Nanotechnology Industries Association (NIA)}

Similar to CEFIC, the Nanotechnology Industries Association (NIA) backed option five in the public consultation organised by the European Commission in 2013 [49].

The NIA prefers option 5 to support innovation and competitiveness, and it expresses fear that taking on board elements from option 2 would run the risk of stigmatising nanomaterials. In regard to option 4, the NIA argues that this option is undesirable, as it has 'significant potential to drive up the costs and create an unbalance between cost and safety'. Option 6 is considered to be scientifically unjustified and therefore is not supported by the NIA [68].

When it comes to the "nano-patch," suggested by CIEL and others, the NIA is of the opinion that there is no need for a separate nanomaterial regulation, and adjustments are possible to applicable REACH annexes. In addition the NIA has accused NGOs of trying to 'fix something that is not broken’ [55].

In short, the NIA aims at providing a framework of shared principles for the safe, sustainable and socially supportive development and use of nanotechnologies, as well as a publically and regulatory supportive environment for the continuing advancement and establishment of nanotechnology innovation. The NIA wants to achieve these aims through providing support to nanotechnology industries by forecasting unique areas of competitive advantage using nanotechnologies, helping advance existing markets and developing new market opportunities, as well as interacting with regulators and the public. The latter activities include the publication and consolidation of the positions and statements of nanotechnologies industries, assisting in the development of nanotechnology policies by clarifying the potential of nanotechnologies as part of a net risk/benefit equation, clarifying and demystifying nanotechnologies in the public eye, collaborating with key stakeholder groups to consolidate 
opposing views and securing the innovation and commercialisation of safe and responsible nanotechnologies [69].

When it comes to the regulation of nanomaterials in general, the NIA has repetitively expressed concerns about revisions implemented in various pieces of EU legislation, arguing that 'product labelling, and requirements that are already in place for registers and annual notifications, increases cost, uncertainty and burdens for industry’ [70].

Furthermore, it finds that 'REACH is a suitable regulatory framework for nanomaterials', that '...there is no need for a separate nanomaterial regulation' and that 'adjustments are possible to applicable REACH annexes’ [55].

When it comes to nanosilver specifically, the NIA takes the position that the long-awaited and very delayed work of the OECD ‘... will answer stakeholder questions in a globally coordinated fashion and provide reliable performance standards for the nanotechnology industries. Finally, it also concentrates on coordinating its members' activities when refuting concerns about nanosilver expressed by the BfR [57, 61].

\section{The Silver Nanotechnology Working Group (SNWG)}

The institute aims overall at serving as the industry's voice in relation to increasing public understanding of the many uses and values of silver, but its specific goals include, among others, encouraging the development and uses of silver and silver products, helping develop markets for silver and its products and developing methods for improving the welfare of the silver industry [71].

The SNWG began its work in January 2009 and aims at providing 'an industry-wide effort to foster the collection of data on silver nanotechnology in order to advance the science and public understanding of the beneficial uses of silver nanoparticles in a wide range of consumer and industrial products’ [72]. 
'Regardless of form, all silver antimicrobial materials function through the action of silver ions', according to SNWG, as 'the function of nanosilver is fundamentally no different from any other antimicrobial silver materials... Historical analysis reveals that the toxicological record is based on ionic and colloidal (nano) silver materials’ [61].

When it comes to the risks involved in using the material, the SNWG has argued that the current characterisations, both for particles used and for the dosage in past toxicological studies, are insufficient and they do not meet the standards of modern toxicology [64]. SNWG argues that nanosilver has been used safely in dermal wound care for decades, it has been safely used in direct aquatic applications for decades, it has been made and used by man for decades and that nanoscale silver products have been safely regulated since the 1950s [73].

The SNWG furthermore provided background materials for one of the most highly cited scientific articles on nanosilver, by Nowack et al. [4], which concluded that '[t]he implications of this analysis for policy of nanosilver is that it would be a mistake for regulators to ignore the accumulated knowledge of our scientific and regulatory heritage in a bid to declare nanosilver materials as new chemicals, with unknown properties and automatically harmful simply on the basis of a change in nomenclature to the term "nano", [4].

\section{The European Precious Metal Federation}

The European Precious Metal Federation (EMPF) is important, as it organised the REACH registration of silver metal, silver nitrate and disilver oxide in October 2010, which again was updated in 2014 to include nanosilver [60, 63].

\section{Primary producers}


A few primary producers have engaged in the public debate about the risk assessment and regulation of nanosilver. For instance, in response to the Bfr, the German nanosilver manufacturer RAS Materials argued that the BfR lacked any form of reference to the current scientific understanding of the matter and that BfR was contradictory in doubting the antimicrobial functionality of silver ions, on the one hand, while simultaneously requesting an investigation into an unknown risk associated with silver nanoparticles, on the other hand. The call by BfR for more scientific research was perceived by the company as 'incomprehensible' and 'an attempt to buy time for the policymakers’ [57, 61]. RAS Materials was established in 2010 as a spin-off of the rent a scientist $\mathrm{GmbH}$, and the objective of the company is the manufacture and distribution of advanced nanomaterials [74].

HeiQ Materials AG, which makes an antimicrobial silver additive for textiles, has also spoken out against the BfR's opinion, arguing that in real-life circumstances 'real-world studies' have observed no acute toxicity or sensitisation in relation to nanosilver, that textiles treated with silver have no impact on the health of human skin and that nanosilver particles can be effectively removed from waste streams [61]. HeiQ Materials AG was established in 2005 as a spin-off from the Swiss Federal Institute of Technology and has 30 employees. It considers environmental protection and business sustainability as paramount [75].

\subsubsection{Environmental and consumer NGOs}

\section{European Environment Bureau}

As noted in the DPSIR analysis, a number of environmental and consumer NGOs have been calling for a so-called "nano-patch.” One of the signers of the position paper on the regulation of nanomaterials is the European Environment Bureau (EEB) [76], which is Europe's largest coalition of grassroots environmental organisations and engages in a wide variety of environmental 
issues, such as biodiversity, waste, climate change, chemicals and nanotechnology. The EEB's vision is to secure prosperity and peace for all, which depends on a rich, clean and healthy environment, that we live in responsible societies that respect the carrying capacity of the planet and preserve it for future generations. Core values of the EEB are sustainable development, environmental justice, global equity, transparency, participatory democracy and shared but differentiated responsibilities. It promotes the principles of prevention and precaution - and the polluter pays.

When it comes to nanomaterials in general and the six policy options put forward by the European Commission, the EEB has argued that 'option six, which foresees additional emphasis on generating targeted information to reduce uncertainty', would be the only one acceptable 'as it considers scientific recommendations'. Option five, which was preferred by CEFIC and NIA, is perceived as 'inconsistent, unacceptable and not democratic', as it gives nanomaterials specific regulatory exemptions and dismisses safety concerns [49].

The EEB has furthermore been calling continuously for regulatory measures that go beyond revisions for the REACH annexes. For instance, in response to the second regulatory review by the European Commission, the EEB argued that while 'The SWP acknowledges the existence of possible risks due to exposure to nanomaterials, and considers that REACH does not currently deliver adequate or reliable information to enable the concerns to be assessed or addressed. It further takes note of the failure of any existing tool to address, in a reliable manner, the current knowledge gap, meaning that citizens are prevented from exercising their right to know about the hazards, risks and uses of nanomaterials'. Moreover, the Commission failed, in that '[it] only considers a limited amendment to the REACH annexes, which is insufficient to close existing loopholes, and manifestly insufficient to overcome the current lack of information on nanomaterials in products. When information is lacking on the toxicity of a substance, rather than assuming that 
no data means no harm, the Commission should enforce a precautionary approach and regulate the production and collection of data, and adequately restrict, ban, or tightly regulate the marketing of the substance concerned' [77].

When it comes to nanosilver, the EEB [78] has argued that releasing it into the environment should no longer be allowed, citing sufficient evidence to suggest that it may be harmful to various organisms and ecosystems and calling for products containing nanosilver to be assessed for safety throughout their whole lifecycle, requiring assessment beyond the use phase and including end-of-life impacts [78]. In relation to a discussion about revising the RoHS directive, the EEB called for a restriction by 2014 on the use of nanosilver and that this restriction should be set to the detection limit in homogenous EEE parts [79].

\section{Center for International Environmental Law}

The Center for International Environmental Law (CIEL) is an NGO that works actively to strengthen and use international law and institutions to protect the environment, promote human health and ensure a just and sustainable society, by providing legal counsel and advocacy, policy research and capacity building [80].

As noted under the "R" of the DPSIR analysis, CIEL has similarly argued that nanomaterials are 'just out of REACH' of European regulations, calling for a stand-alone regulation or a "nano-patch" for nanomaterials, which, instead of reopening REACH, would establish clear, legally binding provisions for nanomaterials and create a transparent and predictable legal environment for their safe production and use in the EU. Re-opening REACH is perceived as politically impossible and could invite further weakening of the current regulation, but a "nanopatch” for REACH would provide added flexibility, according to CIEL [81]. 


\section{BEUC - The European Consumer Organisation}

BEUC is the European Consumer Organisation and acts as an umbrella organisation in Brussels for its members, for example national consumer organisations. BEUC focuses on EU decisions and developments likely to affect consumers, and it focuses especially on eight areas, including consumer rights, sustainability, safety, health and energy [82].

According to BEUC, the concept of sustainability underpins all of their campaigns, and they work to ensure that consumer policy at EU level is sustainable for all, not only regarding respect for and protection of the environment, but also in reducing negative social and economic impacts while improving well-being for all, without compromising the needs of our children's grand-children [82]. BEUC furthermore works for the empowerment of consumers through competitive markets, albeit complemented by health and safety safeguards, and where consumers cannot be empowered, regulatory measures must protect their economic and legal interests [83].

When it comes to nanosilver, BEUC has called for the adaptation of REACH and sectorspecific legislation, to address nanomaterials adequately, as well as an independent assessment of their safety by scientific bodies in certain sectors, including food, cosmetics and textiles. Similarly, steps that would improve the transparency and availability of information on nanomaterial content are suggested, including establishing a public inventory of products and mandatory labelling requirements for certain industries $[84,85]$.

\subsubsection{The scientific community}

The scientific state of knowledge has been summarised above under the "P" and "I" of the DPSIR analysis. When it comes to the regulation of nanomaterials in general and nanosilver specifically, scientific researchers seldom engage actively in public discussions. When it comes to nanosilver, Nowack et al. [4] have argued that it is not a new discovery; it has been used in various products for 
over a hundred years, and its antimicrobial effects have been known from the earliest days of its use. Therefore, they find that it would be a mistake for regulators to ignore this knowledge and that declaring nanosilver as a new chemical would have profound implications for its registration under REACH [4].

Hansen and Baun [2] and Hansen [86], on the other hand, have called for the European Commission to regulate nanosilver and for: 1) the development of clear rules defining the ingredients of a product, using the unique physical and chemical attributes of the ingredients to track production, use and environmental release/dispersal data, (2) an assessment of what information is needed to oversee the safe use of nanosilver and (3) an evaluation of the relevance and shortcomings of current silver-relevant regulations [86].

\subsection{Evaluation of stakeholders' importance and influence}

It is often hard to evaluate the overall importance and influence of various stakeholders. One way, however, to achieve this task is to investigate the resources and organisational settings of the various stakeholders and categorise their importance and influence into high, medium and low.

\subsubsection{European institutions}

As the Council of the European Union and the European Parliament are the EU's two law-making institutions, their importance is assumed to be high. The Council of Europe has never expressed its explicit opinion on nanosilver specifically or on nanomaterials in general, and therefore its level of influence is estimated to be medium. In contrast, the European Parliament is estimated to have a high level of influence, as it has been very outspoken about the need for REACH revision when it comes to nanomaterials. Furthermore, the EP has steadily been gaining more and more power over recent decades. 
Similar to the Parliament, the European Commission is also believed to have a high level of importance, as it is the only entity in the EU that can propose new legislative measures. Internal disagreements within the Commission among the DGs mean that it is not making the most of its potential, so its importance is therefore deemed to be on the same level as Parliament. When it comes to influence within the Commission, DG GROW is believed to have more influence compared to DG Environment, simply due to the amount of resources that it has available. DG Grow has approximately 1400 staff [51], whereas DG Environment had just over 500 staff members in 2010, down from 550 staff members in 2002 [87, 88].

Regarding the actual drafting and development of policy apropos the regulation of nanomaterials, the European Chemical Agency has limited importance, but it is considered to be of medium importance, simply because it is responsible for the day-to-day implementation of REACH and would also be responsible for the actual implementation of any annex revisions and the regulation of nanomaterials and nanosilver should they occur. ECHA has a total staff of around 500, but it is under pressure to cut this number despite the fact that REACH is still under implementation $[50,89]$.

ECHA's influence is estimated to be high, as it is responsible for the day-to-day implementation of REACH and therefore has great influence over how nanomaterials are risk assessed and regulated in reality. ECHA will also be responsible for the revision of the REACH annexes, should it be decided that they need to be revised, and for revising the technical guidance documents [7] that industry can use as a benchmark for how to risk assess nanomaterials. Consequently, ECHA has a lot of influence in the implementation of REACH when it comes to nanomaterials. Furthermore it is the only official body that can truly evaluate how nanomaterials are currently being registered and risk assessed by industry - and whether these arrangements are satisfactory. 


\subsubsection{Member states of the European Union}

Regarding the regulation of nanosilver, the importance European member states is evaluated as medium. It should, however, be noted that it is hard to assess their importance, as there has been a "surprising” lack of general emphasis on their influence over legislative decision-making in Europe, at least according to Wijen et al. [90]. It is, however, well-recognised that EU policies are important for member states, and their governments are actively involved in making these policies, as they send ministers and public officials to various meetings held and organised by European institutions, they nominate commissioners to the Commission, have significant influence on who becomes a member of the European Parliament from their country and, finally, they enforce much of the negotiated legislation [90].

Limited research exists on understanding whether and how individual member states influence the character of EU policies, and little is known about the factors that help them to be more or less successful in policy negotiations [91]. Aksoy [91] examined the role member states’ voting and proposal powers played in helping them secure larger shares of funding from the EU budget and the extent to which they succeed in influencing day-to-day decision-making in the EU. Aksoy (2008) found that member states' ability to obtain favourable policy outcomes that closely mirror their preferences can be explained by their 'coalition potential', which is defined as member states' potential to form powerful coalitions with like-minded members who care about the negotiated legislation.

The influence that they can have on how human health and environmental risks are handled on a European level is well-recognised. For instance, in relation to chemical policy, Sweden's ambitious action plan for a toxic-free environment by 2020 has been noted to have had a strong influence on Europe’s Seventh Environment Action Programme [92]. By taking the lead on 
chemicals policy, Sweden has put itself in a strong position to influence EU policy, according to Chemical Watch: 'Sweden really pushed for this to be included in the action plan, when it was being negotiated', and 'as guided by the Swedish goals, the Commission aims to pay more attention to chemicals in products, nanomaterials and mixtures', according to a representative from the European Commission’s DG Environment [92].

Sweden's influence will not be limited to ensuring that the European Commission produces a strategy for achieving a non-toxic environment; it will also have a profound impact on the development and implementation of the strategy itself, as negotiators have only agreed to include the concept of a non-toxic environment if Sweden assists in creating the details of the strategy [92].

Similarly to Sweden, Denmark has been recognised for putting pressure on EU policy on endocrine-disrupting chemicals and for being a "trailblazer" in the debate on criteria required for the identification of endocrine-disrupting chemicals. In addition, in collaboration with other member states, it has called for the introduction of more relevant test methods to demonstrate the endocrine-disrupting effects of substances [92].

Regarding nanomaterials and nanosilver specifically, it could be argued that countries such as Sweden, Denmark, Germany, Belgium, France and the Dutch form what Aksoy [91] termed a 'coalition of like-minded members', as France, Belgium and Denmark have implemented mandatory national reporting programmes when it comes to nanomaterials, while other member states such as the Dutch have been pressing for an EU-wide regulatory solution [54]. Overall, the influence of member states is estimated to be medium.

\subsubsection{Environmental and consumer NGOs}


Similar to member states, the importance of various environmental and consumer NGOs is also considered to be of medium importance, simply because they and their right to provide input are considered to be essential by European legislators. NGOs have been long-recognised as a significant component of civil society by the EC, which believes that they provide valuable support for a democratic system of government [93]. The EC have furthermore stated that NGOs 'engage in regular dialogue with public authorities with a view to ensuring better implementation of EU initiatives and policies in the EU countries' [94]. Over the years, the EC has provided substantial funding for NGOs in various fields, such as humanitarian aid, social activities and the environment. Most recently, 3.4 billion $€$ was set aside for the period of 2014-2020 to fund NGO framework partnership agreements (FPAs). Specifically, NGO-operating grants are available to 'support certain operational and administrative costs of non-profit making entities which pursue an aim of general Union interest, are primarily active in the field of environment and/or climate action and are involved in the development, implementation and enforcement of Union policy and legislation' [95].

Examples of an environmental NGO and a consumer NGO that has been actively involved in the discussions about risk assessment and regulation of nanosilver are the EEB and BEUC. The EEB and BEUC work to influence EU policymaking, in order to improve or protect environment laws and consumer rights and interests in Europe, mostly through dialogue with European institutions. In this process, the EEB and BEUC also supply information to the public, its members and European institutions through articles, reports and papers, as well as expert comment, analysis and recommendations, on most of the latest environmental issues [96, 97]. Besides receiving funding from foundations and the EC, the EEB has also received financial assistance from a range of environmental ministries over the years, such as the Finnish, Danish, Dutch, British, German and 
Spanish [97] departments, which underlines that many consider their work very important and worthy of support.

However, overall, the influence of EEB and BEUC is still estimated to be low, simply due to the limited resources that they have at their disposal with an annual budget in 2013 of about $€ 2.2$ million, of which about $€ 800,000$ came from foundations and another $€ 800,000$ from the European Commission [98]. Similarly, the operational budget of BEUC in 2013 amounted to $€ 3,196,000$, the biggest contributors of which came from the national member organisations (54\%) and EU funding (41\%) [99].

Another environmental NGO that has been involved in the discussions is CIEL. Similar to the EEB, CIEL's total revenue in 2014 was about $€ 2.5$ million, and according to their annual report they received funding from a range of different foundations, such as the Oxfam America, V. Kann Rasmussen Foundation, the Swedish Foundation for Nature Conservation and UNEP [100]. As with EEB, CIEL's importance is considered to be medium, whereas their level of influence is considered to be low to medium, due to the high level of discussions they have been able to generate as a result of their suggested “nano-patch”.

\subsubsection{Businesses and their branch organisations}

Individual businesses, such as RAS Materials and HeiQ Materials AG, are assumed to have medium importance in relation to the development of nanosilver regulation, as they represent examples of innovative small- and medium-sized enterprises (SMEs) and there is a high level of focus in the EU on creating an overall good business environment for these types of business. This has been reflected directly in, for instance, ECHA calling for 'radical positive discrimination for small- and medium-sized enterprises (SMEs)' in relation to data-sharing costs under REACH [50]. Although the importance of individual SMEs is assumed to be medium, their influence is evaluated 
as being limited. There is no doubt that individual businesses can provide strong and persuasive arguments for different perspectives that are very relevant for regulatory decisions, as RAS Materials and HeiQ Materials AG have proven for nanosilver, but their direct influence is still considered to be limited.

Whereas individual businesses might have limited influence, branch organisations, such as CEFIC, NIA and EPMF, can have a lot of influence. This is especially the case for CEFIC, which simply due to its size has to be considered highly important and must also be assumed to have a high level of influence. CEFIC is the trade association for the European chemical industry, and it represents more than 20 national federations and 650 members from across the EU. The chemical industry is massive in the EU and, according to CEFIC, it currently comprises approximately 29,000 companies, employing roughly 1.2 million people directly and a further 3-4 million people indirectly. Turnover generated is more than €500bn and net exports are nearly €50bn [101].

No information has been found on staff numbers and annual budget when it comes to branch organisations such as the NIA, EMPF and the Silver Nanotechnology Working Group. Nevertheless, their importance and influence are assumed to be not as significant as CEFIC, although they should not be neglected. The NIA was founded in 2005 by a group of companies from across a range of industry sectors, such as healthcare, chemicals and automotive, and it provides a sector-independent voice for industrial nanotechnology supply chains. Members include BASF, 3M, Johnson \& Johnson and Solway, amongst others. As with CEFIC, the NIA is constantly involved in the ongoing debate about the risk assessment and regulation of nanomaterials, and it is represented in a number of FP7 and Horizon 2020 research projects in the EU as well as within the OECD Working Party on Manufactured Nanomaterials and ISO standardisation bodies [102]. The level of influence of the NIA is evaluated to be medium and on the same level as CEFIC, due to the fact that it has been able to establish itself as the choice of the nanotech business industry and seems 
to be cited everywhere when it comes to discussions about the risk assessment and regulation of nanomaterials in general and nanosilver specifically.

The importance and level of influence of the Silver Nanotechnology Working Group (SNWG) and EPMF is considered to be low. The SNWG is a working group established by The Silver Institute, which is a non-profit international association populated by members from leading silver mining houses, refiners, bullion suppliers, manufacturers of silver products and wholesalers of silver investment products. Similarly, the European Precious Metals Federation (EPMF) is a nonprofit association that represents the European precious metals industry and coordinates the industry’s advocacy activities at European level [104, 105].

\subsubsection{The scientific community}

Overall, the importance and influence of the scientific community is evaluated as being low when it comes to the regulation of nanosilver, as risks and scientific risk assessment in this regard have only been subject to very limited discussion in the public domain and in stakeholder's discussions on how to regulate the use of nanosilver.

The lack of a useful risk assessment was recognised in 2013 as a general problem by three scientific committees in the European Commission. In their opinion, on making risk assessment more relevant for risk management [106], 'risk assessments as currently carried out do not inform the risk management process as well as they should'.

\subsubsection{Importance and influence diagram}

Once all the stakeholders have been evaluated and categorized in regard to their importance and influence, an importance and influence diagram can be generated according to stakeholder analysis and theory. See figure 1 for an illustrative overview of the importance and influence of various 
stakeholders when it comes to regulation of nanosilver. It should be noted that lack of specific information and access to information about staff number, annual budget, etc. makes it hard to make a uniform detailed analysis.

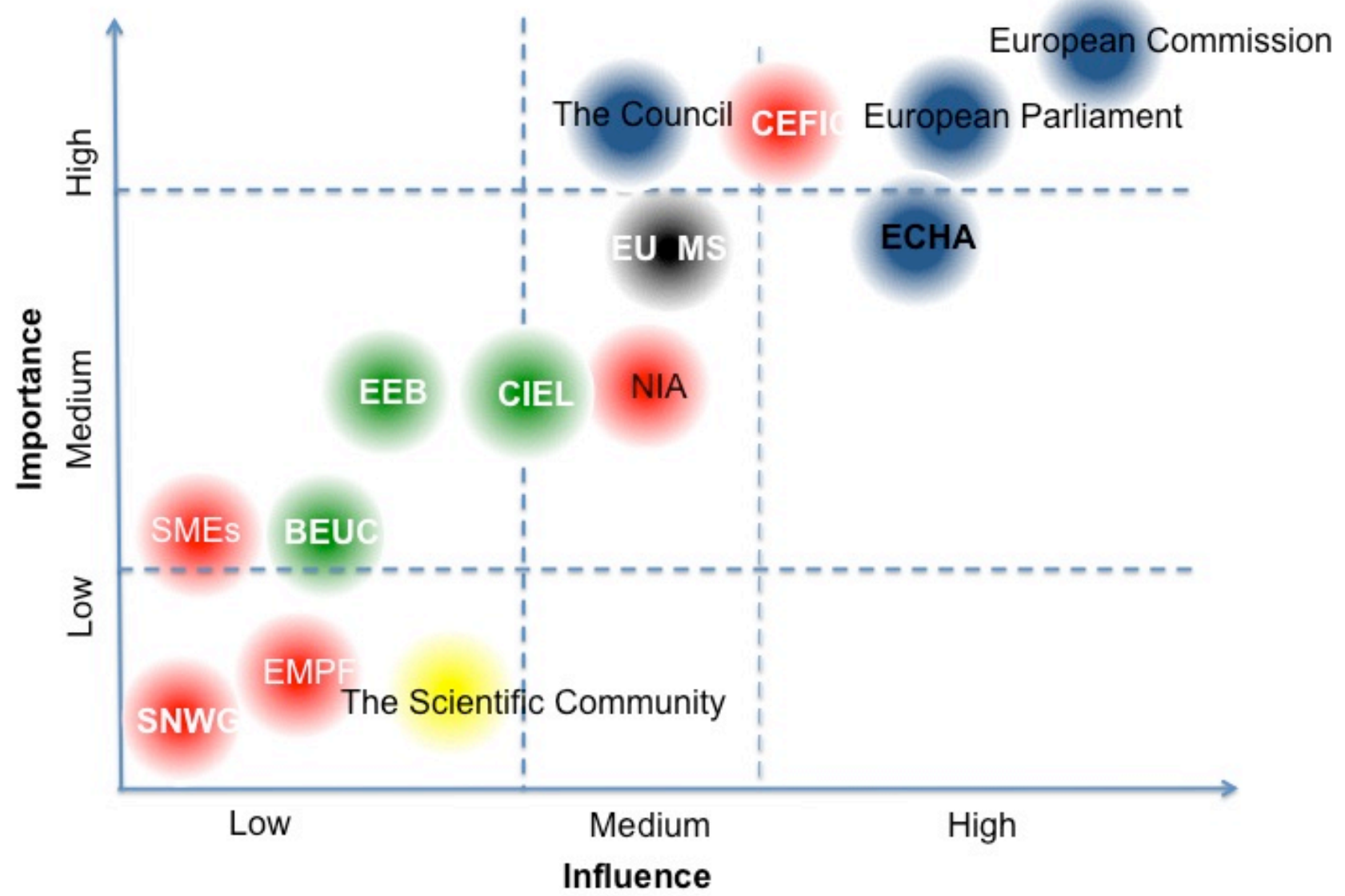

Figure 1: Stakeholder importance-influence diagram in relation to nanosilver

\section{Discussion}

A great deal of concern has been raised about the use of nanosilver, especially in regard to its widespread prevalence in everyday consumer products. Many discussions about the risks of nanosilver have centred on whether its use is toxic to humans and the environment. The preferred and seemingly only scientific approach used to make arguments for and against regulation has been 
chemical risk assessment, albeit without the realisation that chemical risk assessment has a tendency to be very reactive and focuses on studying risk in ever and ever greater detail. Furthermore, chemical risk assessment is based on a utilitarian way of thinking and takes a hierarchist point of view of nature $[12,13]$, which not all stakeholders in the debate about how to regulation nanosilver can necessarily automatically be expected to agree with. In this paper we set out to explore what would happen if we used DPSIR analysis, which is based on land ethics and is more closely related to the egalitarian view of nature, or if we used stakeholder analysis, which has a more libertarian perspective and reflects an individualist perspective on nature.

Specifically, we used DPSIR analysis to understand and map the known risks and uncertainties associated with the use and regulation of nanosilver. From the mapping of pressures in the DPSIR analysis, it is clear that the use of nanosilver could potentially put a lot of pressure on human health and the environment, as it has been associated with a number of adverse endpoints, the development of multi-resistant bacteria and ecotoxicity in relation to algae, crustaceans, fish and nitrifying bacteria. Although it is hard to predict its impact, the DPSIR analysis revealed that it could be dire, and it also revealed that the current state is not very good and is already under a lot of pressure, especially when it comes to the development of bacterial resistance and the state of European lakes and rivers. A range of different regulatory options was identified via the DPSIR analysis, and it seems that they included keeping the status quo to implement a so-called "nanopatch" that would result in the drafting of new legislation for nanomaterials in general and nanosilver-specific changes in current European chemical, biocide, medical and food legislation. When it comes to limiting the spread of resistance, it is unclear as to how at least some of the proposed regulatory options, such as keeping the status quo or relieving industry of some of its requirements under REACH, can and would address or relieve the identified pressures. From the DPSIR analysis, it is evident that drafting any new legislation for nanomaterials in general and 
implementing nanosilver-specific changes in the current European chemical, biocide and medical legislation is the optimal policy response, along with limiting the overall use of nanosilver.

Interestingly, none of the regulatory options currently being discussed among stakeholders seem to address the Drivers identified for using nanosilver, namely using nanotechnology R \& D to create jobs and growth in Europe, and it seems that addressing these drivers is somewhat disconnected from the current discussion about nanosilver regulation and, perhaps, nanomaterials and nanotechnology in general (see Figure 2). This might be related to the tension that currently exists between the identified drivers aimed at developing and promoting nanotechnology to obtain growth and jobs, whereby many of the identified regulatory options could arguably be assumed to be additional administrative burdens, thereby hampering the ability of create growth and employment.

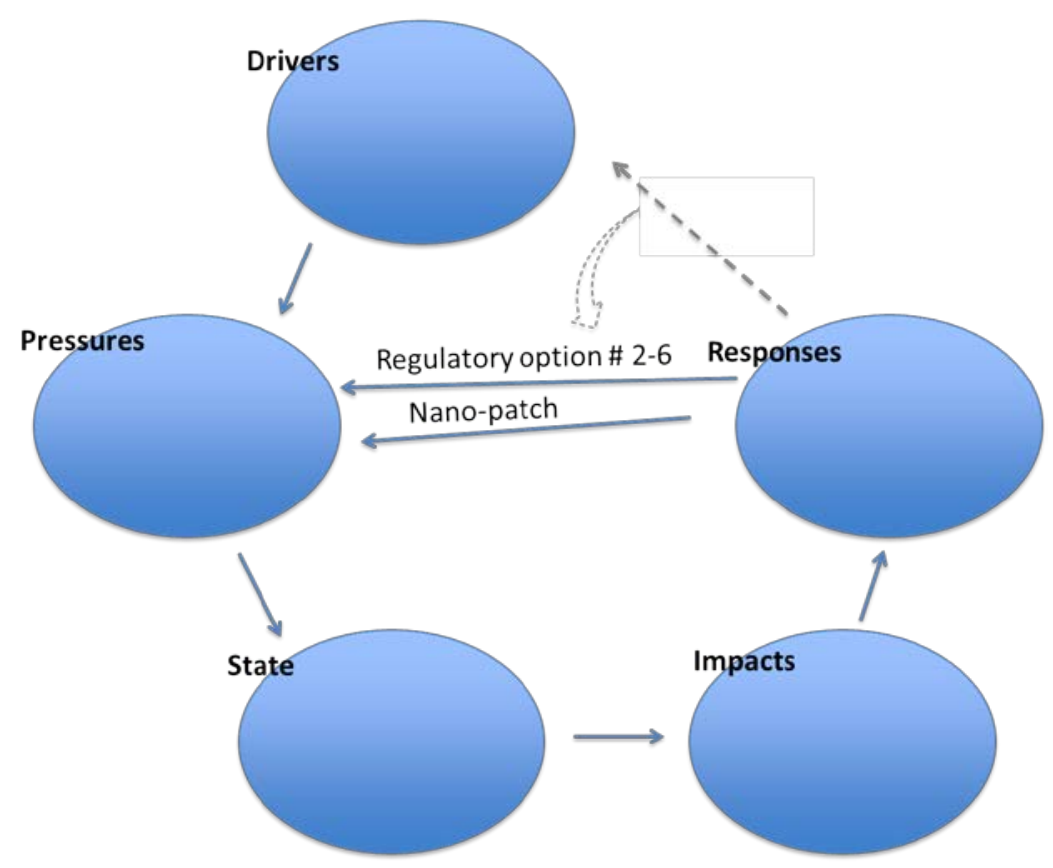

Figure 2: Illustration of how the drivers seem to have become disconnected from the current discussion about the regulation of nanosilver. 
In order to qualify the identified potential policy responses, we carried a stakeholder analysis and explored possibilities for reaching consensus among stakeholders in regard to the regulation of nanosilver. It is clear from the stakeholder analysis that the European Commission is very powerful in this regard, as it holds the right to propose new legislation or revisions to existing legislation when it comes to nanomaterials. All the other stakeholders seem almost powerless in comparison, at least until the Commission comes forward with a proposal. Of course, the other stakeholders have different ways and means of gaining influence. For instance, some business branch organisations, such as CEFIC and NIA, have a lot of potential influence, due to the resources that they have available, to make sure that the European Commission and other decision-makers hear what they have to say and take note of their concerns.

The influence and importance of the scientific community was found to be low, which might come as a surprise for some. However, it is a well-known phenomenon that when issues become more complex and stakeholders' stakes in the outcome become greater, the greater the infusion of values and non-scientific knowledge in the debate, thereby resulting in the relative weight of science decreasing $[107,108]$.

Especially, consumer and environmental NGOs and SMOs require the special attention of decision-makers, as they seem to have a lot of interests but very little influence and power compared to the more established regulatory and industrial stakeholders. NGOs could have a lot of potential influence if they can engage the public, and there is a public outcry for member state authorities and the European Commission to address the regulation of nanosilver. This also highlights one of the limitations of our stakeholder analysis, which is that important stakeholders such as the public might be missed or not identified due to the methodology used to complete the stakeholder identification, or due to the fact that not all stakeholders speak up in public and that their interests and views can be hard to identify. There are and have been many opportunities for 
members of the public to engage in the debate, but in general there have been only limited attempts to include the public actively in these discussions. This is despite the European Commission having publicly recognised that dialogue with the public is essential for a number of reasons. It is needed in order to 1) focus attention on issues of real concern, 2) ensure that nanotechnology is developed in a safe and responsible manner, 3) make certain that societal impacts are examined, 4) safeguard that ethical principles are adhered to when it comes to the potential health, safety or environmental risks and, finally, 5) prepare for possible regulation [20].

Besides the public, an obvious stakeholder that was not identified via the method that we used is the Council of the European Union, which undoubtedly has a lot of power and influence but rarely communicates its interests and views in public. Another stakeholder that one could consider is nature, as the use of nanosilver could potentially have serious implications on the state of the environment, as it is well-known to be ecotoxic. Whether nature is and should be considered a legitimate stakeholder that has a right to ethical considerations is a discussion that is as old as the field of environmental ethics itself. Freeman et al. [109] have argued that the question is meaningless, because nature does not have a choice that can speak for it. Obviously, this argument can and has been contested, and it seems clear that many environmental NGOs try to speak on behalf of nature, at least according to themselves.

Interestingly, none of the policy options identified as optimal via DPSIR analysis was deemed to be implementable via the stakeholder analysis, as industry and NGOs seem to have fundamentally conflicting views. For instance, keeping the status quo is unacceptable to NGOs, whereas the nano-patch is unacceptable to industry. These conflicting views might be explained by the different interests of these specific stakeholders and may fundamentally come down to different ethical perspectives on nature and the environment, and whether or not the environment and ecosystems have a "carrying capacity” when it comes to the use of nanosilver [13]. 
Nevertheless, the combination of using DPSIR and stakeholder analysis seems to be a promising approach. One of the benefits of using DPSIR in combination with stakeholder analysis is that they compensate for each other's limitations. For instance, DPSIR analysis very often assumes that there is a "simple" causal relationship between the elements of the DPSIR chain, and according to Svarstad et al. (110), therefore, DPSIR analysis can led to a possible oversimplification of the problem and challenges at hand. Chemical risk assessment could be argued to have the same limitation (111), but this is addressed by stakeholder analysis, which does not require any form of causal relationship to be established and thereby opens up the mapping of the full complexity of whatever issues is being considered. It has been argued furthermore that DPSIR is not a neutral framework and it tends to favour preservation and conservationism; additionally, results will inevitably depend on perspective, and there is limited guidance on how to deal with multiple attitudes and definitions relating to stakeholder issues. These limitations are addressed in full by stakeholder analysis, as it focuses on mapping and understanding stakeholders' perceptions, their points of view and the influence and hierarchy of power, and understanding the micro and macro political, economic and social impacts. As a result, one can avoid forgetting important aspects, implementation failures and disregarding needs/desires of various stakeholders and be clear about which needs/desires are disregarding. This again enables the possibility for clear and transparent communication. It is important to note that stakeholder analysis has a number of limitations, some of which have already been alluded to, as there is a risk of forgetting important stakeholders that may be less important or influential.

Many of these limitations are addressed by DPSIR analysis, as it focuses on providing effective solutions for "real-world problems," regardless of whether these solutions might adversely affect powerful and influential stakeholders. It furthermore, as noted by Tcherning et al. [17], provides decision support by means of showing solid evidence on a range of possible decisions that 
could be implemented rather than by presenting predetermined solutions. In the case of regulation of nanosilver, this would make the discussion much more proactive and focused on what can be done now and what societal stakeholders can reach consensus about.

\section{Acknowledgements}

The study is part of the ENVNANO project, kindly supported by the European Research Council (Grant no. 281579).

\section{References}

1) The Nanodatabase. Available: www.nanodb.dk. Accessed 27-04-2015.

2) Hansen, S.F., Baun, A. 2012. When Enough is Enough. Nature Nanotechnology 7: 409-411

3) Hansen SF, Maynard A, Baun A, Tickner JA, Bowman DM (2013) Nanotechnology — early lessons from early warnings. In Gee D et al. (Eds.) Late lessons from early warnings: science, precaution, innovation. Copenhagen: European Environment Agency Available: http://www.eea.europa.eu/publications/late-lessons-2

4) Nowack B, Krug HF, Height M (2011) 120 Years of Nanosilver History: Implications for Policy Makers. Environmental Science \& Technology 45(4): 1177-1183

5) SCENIHR (2014) Opinion on Nanosilver: safety, health and environmental effects and role in antimicrobial resistance. Brussels: Scientific Committee on Emerging and Newly Identified Health Risks, European Commission

6) WHO. 2013. Nanotechnology and human health: Scientific evidence and risk governance. Report of the WHO expert meeting 10-11 December 2012, Bonn, Germany. Copenhagen, WHO Regional Office for Europe, 2013. 
7) ECHA (2015) Guidance on REACH. Available: http://echa.europa.eu/guidancedocuments/guidance-on-reach. Accessed 27-04-2015.

8) ECHA (2008) Guidance on information requirements and chemical safety assessment Chapter R.10: Characterisation of dose [concentration]-response for environment. Helsinki: European Chemical Agency. http://echa.europa.eu/documents/10162/13632/information_requirements_r10_en.pd

9) EEA (2001) Late Lessons from Early Warnings: The Precautionary Principle 1896- 2000. Copenhagen: European Environmental Agency

10) EEA (2013) Late lessons from early warnings: science, precaution, innovation. European Copenhagen: European Environmental Agency.

11) Tickner J (2006) Risk Assessment is not Enough to Protect Public Health. Rationale for the Precautionary Principle. In: Toscano W and Robson M. Risk Assessment in Public Health. Jossey Bass. pp 423-462.

12) Shwarz, M., Thompson, M., 1990. Divided We Stand: Redefining politics, technology and social choice. University of Pennsylvania Press.

13) Thompson M (2012) Understanding Environmental Values: A Cultural Theory Approach. Available:

https://www.carnegiecouncil.org/publications/articles_papers_reports/710.html/_res/id=sa_Fil e1/711_thompson.pdf. Accessed 27-04-2015.

14) Freeman RE, Phillips RA (2002) Stakeholder Theory: A liberation defense. Business Ethics Quarterly 12(3): 331-349

15) Davidson M (2009) Acceptable Risk to Future Generations. In: Asvild L and Roeser S (Eds.). The Ethics of Technological Risk. Earthscan, pp. 77-91. 
16) Gabrielsen P, Bosch, P (2003) Environmental Indicators: Typology and Use in Reporting. Copenhagen: European Environmental Agency.

17) Tscherning K, Helming K, Krippner B, Sieber S, Gomez y Paloma S (2012) Does research applying the DPSIR framework support decision making? Land Use Policy 29: 102-110.

18) Rapport DJ, Gaudet C, Karr JR, Baron JS, Bohlen C, Jackson W, Jones B, Naiman RJ, Norton B, Pollock MM (1998) Evaluating landscape health: integrating societal goals and biophysical process. Journal of Environmental Management (1998) 53: 1-15.

19) OECD (1993) Environment monographs no. 83 OECD core set of indicators for environmental performance reviews - A synthesis report by the Group on the State of the Environment. OCDE/GD(93)179. Paris: OECD.

20) European Commission (2004) Towards a European Strategy for Nanotechnology. (COM(2004) 338). Brussels: European Commission.

21) European Commission (2005) Nanosciences and nanotechnologies: an Action Plan for Europe 2005-2009 (COM(2005) 243). Brussels: European Commission.

22) Hansen SF, Gee D (2014) Adequate and anticipatory research on the potential hazards of emerging technologies: a case of myopia and inertia? Journal of Epidemiology and Community Health doi:10.1136/jech-2014-204019

23) Sung JH, Ji JH, Yoon JU, Kim DS, Song MY, Jeong J, Han BS, Han JH, Chung YH, Kim J, Kim TS, Chang HK, Lee EJ, Lee JH, Yu IJ (2008) Lung function changes in Sprague-Dawley rats after prolonged inhalation exposure to silver nanoparticles. Inhalation Toxicology 20: $567-574$

24) Kim YS, Kim JS, Cho HS, Rha DS, Park JD, Choi BS, Lim R, Chang HK, Chung YH, Kwon IH, Jeong J, Han BS, Yu IJ (2008) Twenty-eight-day oral toxicity, genotoxicity, and gender- 
related tissue distribution of silver nanoparticles in Sprague-Dawley rats. Inhalation Toxicology 20:575-583.

25) Mikkelsen SH, Hansen E, Christensen TB, Baun A, Hansen SF, Binderup ML (2011) Survey on basic knowledge about exposure and potential environmental and health risks for selected nanomaterials, Environmental Project 1370. Copenhagen: Danish Ministry of the Environment. Danish Protection Agency.

26) Cha K, Hong HW, Choi YG, Lee MJ, Park JH, Chae HK, Ryu G, Myung H (2008) Comparison of acute responses of mice livers to short-term exposure to nano-sized or microsized silver particles. Biotechnology Letter 1:893-1899.

27) Navarro E, Piccapietra F, Wagner B, Marconi F, Kaegi R,Odzak N, Sigg L, Behra R (2008) Toxicity of silvernanoparticles to Chlamydomonas reinhardtii. Environmental Science and Technology 42(23): 8959-8964

28) Griffitt RJ, Luo J, Gao J, Bonzongo J, Barber DS (2008) Effects of particle composition and species on toxicity of metallic nanomaterials in aquatic organisms. Environmental Toxicology and Chemistry, 27(9): 1972-1978.

29) Georgantzopoulou A, Balachandran YL, Rosenkranz P, Dusinska M, Lankoff A, Wojewodzka M, Kruszewski M, Guignard C, Audinot J, Girija S, Hoffmann L, Gutleb AC (2013) Ag nanoparticles: size- and surface-dependent effects on model aquatic organisms and uptake evaluation with NanoSIMS. Nanotoxicology, 7(7): 1168-1178.

30) Gaiser BK, Biswas A, Rosenkranz P, Jepson MA, Lead JR, Stone V, Tyler CR, Fernandes TF (2011) Effects of silver and cerium dioxide micro- and nano-sized particles on Daphnia magna. Journal of Environmental Monitoring, 13(5): 1227-1235. 
31) Gaiser BK, Fernandes TF, Jepson MA, Lead JR, Tyler CR, Baalo (2012). Interspecies comparisons on the uptake and toxicity of silver and cerium dioxide nanoparticles. Environmental Toxicology and Chemistry 31(1): 144-154.

32) Hu Z (2010) Impact of Silver Nano-particles on Wastewater Treatment, WERF Report U3R07. London: IWA Publishing.

33) EEA 2015. The European Environment State and Outlook 2015. Copenhagen: European Environment Agency. Available: http://www.eea.europa.eu/soer-2015/synthesis/report/3naturalcapital. Accessed 27-04-2015

34) World Health Organization (2014) Antimicrobial resistance Fact sheet $\mathrm{N}^{\circ} 194$. Available: http://www.who.int/mediacentre/factsheets/fs194/en/. Accessed 27-04-2015

35) Aitken RA, Bassan A, Friedrichs S, Hankin SM, Hansen SF, Holmqvist J, Peters SAK, Poland CA, Tran CL (2011) Specific Advice on Exposure Assessment and Hazard/Risk Characterisation for Nanomaterials under REACH (RIP-oN 3) Final Project Report. Document reference RNC/RIP-oN3/FPR/1/FINAL. Brussels: European Commission.

36) Stone V, Hankin S, Aitken R, Aschberger K, Baun A, Christensen F, Fernandes T, Hansen SF, Hartmann NB, Hutchinson G, Johnston H, Micheletti G, Peters S, Ross B, SokullKluettgen B, Stark D, Tran L. (2010) Engineered Nanoparticles: Review of Health and Environmental Safety (ENRHES). Brussels: European Commission

37) Wijnhoven SWP, Peijnenburg WJGM, Herberts CA, Hagens WI, Oomen AG, Heugens EHW, Roszek B, Bisschops J, Gosens I, Van De Meent D, Dekkers S, De Jong WH, Van Zijverden M, Sips AJAM, Geertsma RE (2009) Nanosilver - a review of available data and knowledge gaps in human and environmental risk assessment. Nanotoxicology 3(2):109-138.

38) Aitken RJ, Hankin SM, Ross B, Tran CL, Stone V, Fernandes TF, Donaldson K, Duffin R, Chaudhry Q, Wilkins TA, Wilkins SA, Levy LS, Rocks SA, Maynard A (2009) 
EMERGNANO: A review of completed and near completed environment, health and safety research on nanomaterials and nanotechnology. Defra Project CB0409. Edinburgh: IOM,

39) European Parliament and of the Council (2012) Regulation (EU) No 528/2012 Of The European Parliament And Of The Council of 22 May 2012 concerning the making available on the market and use of biocidal products. Official Journal of the European Union 167/1-123.

40) European Commission (2012) Second Regulatory Review on Nanomaterials. Brussels: European Commission.

41) European Commission (2013) Public consultation relating to the REACH Annexes on Nanomaterials. $\quad$ Available: $\quad$ http://www.industriall-europe.eu/Sectors/ChemicalBM/2013/Nano-ques1.pdf

42) Center for International Environmental Law (CIEL) (2014) CIEL and European partners publish position paper on the regulation of nanomaterials at a meeting of EU competent authorities. Available: http://www.ciel.org/Chem/Nano_2Apr2014.html. Accessed 27-042015.

43) Rietbergen-McCracken J, Narayan D (1998) Participation and Social Assessment: Tools and Techniques Washington, D.C.: The International Bank for Reconstruction

44) WHO (2008) Stakeholder Analysis. Available at: http://www.who.int/management/partnerships/overall/en/index1.html

45) Freeman RE (1984) Strategic Management - A Stakeholder Approach. Cambridge: Cambridge University Press.

46) Freeman RE, Phillips RA (2002) Stakeholder Theory: A Libertarian Defense. Business Ethics Quarterly 12(3): 331-349. 
47) Wikipedia (2014) Chemical Watch. Available: http://en.wikipedia.org/wiki/Chemical_Watch. Accessed 27-04-2015.

48) Chemical Watch (2015). Chemical Watch Global Risk \& Regulation News. Available: https://chemicalwatch.com/. Accessed 27-04-2015.

49) Chemical Watch (2013) Industry calls for reduced nano requirements under REACH, CEFIC and NIA respond to EU consultation. Chemical Watch 12 September 2013.

50) Chemical Watch (2014) Dancet asks EU Commission to speed up nano work Pleads for resource flexibility. Chemical Watch 4 December 2014.

51) DG Growth (2015) About us. Available: http://ec.europa.eu/growth/about-us/index_en.htm. Accessed 27-04-2015.

52) DG Environment (2015) Environment Directorate-General. Available: http://ec.europa.eu/dgs/environment/index_en.htm. Accessed 27-04-2015.

53) DG Environment (2015) Welcome. Available: http://ec.europa.eu/environment/basics/home_en.htm. Accessed 27-04-2015.

54) Chemical Watch (2012) Which way now for nanomaterials and REACH? Global Business Briefing. Chemical Watch July/August 2012.

55) Chemical Watch (2012) DG Enterprise, industry deny REACH unable to regulate nanomaterials DG Environment, Enterprise issue separate reactions to nano-patch proposal. Chemical Watch 14 November 2012.

56) Chemical Watch (2011) EU Commission directorates argue over nano definition Directorates disagree over mass vs. particle numbers and size distribution, while NGOs stress dangers of slow progress. Chemical Watch 6 April 2011.

57) Chemical Watch (2010) REACH 2010 deadline will not yield data on nanosilver, Global Business Briefing. Chemical Watch November 2010. 
58) ECHA (2015) Mission. Available: http://echa.europa.eu/about-us/who-we-are/mission. Accessed 27-04-2015.

59) Chemical Watch (2014) Defining nano: should we wait for science? Global Business Briefing. Chemical Watch November 2014.

60) EPMF (2015) Silver (Ag). Available: http://www.epmf.be/index.php/reachconsortiumleft/silver-ag. Accessed 27-04-2015.

61) Chemical Watch (2011) Nanosilver producers refute German institute’s warning Global Business Briefing, Chemical Watch May 2011.

62) BfR (2015) Statutory foundations of BfR. Available: http://www.bfr.bund.de/en/statutory_foundations_of_bfr-1832.html. Accessed 27-04-2015.

63) Chemical Watch (2010) REACH dossier for nanosilver is years away. Chemical Watch 16 November 2010;

64) Chemical Watch (2011) German institute repeats advice against broad use of nanosilver Meeting with industry fails to sway BfR on lack of data to perform health risk assessments. Chemical Watch 13 April 2011.

65) CEFIC (2015) Policy. Available: http://www.cefic.org/Policy-Centre/. Accessed 27-04-2015.

66) CEFIC (2015) Safe and Innovative. Available: http://www.cefic.org/PolicyCentre/Environment--health/Nanomaterials/. Accessed 27-04-2015.

67) CEFIC (2014) Chemicals safety in the value chain How the European chemical industry manages safe of use chemicals. Available: http://www.cefic.org/Documents/Learn\%20and\%20Share/Chemicals-Safety-in-the-ValueChain-Brochure.pdf. Accessed 27-04-2015.

68) NIA (2013) NIA replies to the European Commission Consultation on the Modification of REACH Annexes for Nanomaterials. Available: http://www.nanotechia.org/news/nia- 
press/nia-replies-european-commission-consulation-modification-reach-annexesnanomaterials. Accessed 27-04-2015.

69) NIA (2015) Aims and objectives. Available: http://www.nanotechia.org/aims-objectives. Accessed 27-04-2015.

70) NIA (2014) NIA highlights Concerns over "Red Tape” for Nano in Magazine Interview. Available: $\quad$ http://www.nanotechia.org/news/nia-press/nia-highlights-concerns-over\%E2\%80\%9Cred-tape\%E2\%80\%9D-nano-magazine-interview. Accessed 27-04-2015.

71) Silver Institute (2015) About us. Available: https://www.silverinstitute.org/site/about-us/. Accessed 27-04-2015.

72) Silver Institute (2015) Silver in Nanotechnology. Available: https://www.silverinstitute.org/site/silver-in-technology/silver-in-nanotechnology/. Accessed 27-04-2015.

73) SNWG (2011) Nanosilver. Available: http://www.silverinstitute.org/site/wpcontent/uploads/2013/05/Nanosilver1_2013.pdf. Accessed 27-04-2015.

74) RAS Materials (2015 History. Available: http://rasmaterials.com/index.php/company/history. Accessed 27-04-2015.

75) HeiQ Materials AG (2015) Swiss-made special textile effects - tailored to your needs. Available: http://heiq.com/wp-content/uploads/2013/06/heiq_fly_companyprofile_web.pdf. Accessed 27-04-2015.

76) EEB (2015). European Environmental Bureau Available: http://www.eeb.org/ Accessed 2704-2015.

77) EEB (2012) Stakeholders' Response to the Communication on the Second Regulatory Review on Nanomaterials Brussels, 23 October 2012 Available: 
http://www.eeb.org/EEB/?LinkServID=8CCB13B6-5056-B741-

DB1167713C787E1C\&showMeta=0). Accessed 27-04-2015

78) EEB (2009). Nanotechnologies in the 21th century Nanomaterials - Health and Environmental Concerns, 2: July 2009.

79) European Environmental Bureau (EEB), the Health and Environment Alliance (HEAL), and Women in Europe for a Common Future (WECF) (2010) Position Paper on RoHS revision February 2010. Available:

http://www.eeb.org/tasks/sites/EEB/assets/File/Joint_NGO_Position_RoHS.pdf. Accessed 27-04-2015.

80) CIEL (2015) Who We Are. Available: http://www.ciel.org/About_Us/index.html. Accessed 27-04-2015.

81) CIEL (2012). Nanomaterials "Just Out of REACH" of European Regulations. Available: http://www.ciel.org/Chem/JustOutofREACH_Feb2012.html. Accessed 27-04-2015.

82) BEUC (2015). Who we are. Available: http://www.beuc.org/about-beuc/who-we-are. Accessed 27-04-2015.

83) BEUC (2015) Mission. Available: http://www.beuc.org/about-beuc/mission. Accessed 27-042015.

84) Chemical Watch (2012) Consumer groups call for action on increasing use of nanosilver REACH adaptation, independent assessment of nano material safety urged. Chemical Watch 26 June 2012.

85) ANEC and BEUC (2009) Nanotechnology: Small is beautiful but is it safe? Available: http://www.anec.eu/attachments/Nanotechnology\%20Small\%20is\%20beautiful\%20but\%20is \%20it\%20safe\%20\%C3\%A2\%E2\%82\%AC\%E2\%80\%9C\%20ANEC\%20\&\%20BEUC\%20le aflet\%20on\%20nanotechnology\%20and\%20nanomaterials.pdf). Accessed 27-04-2015. 
86) Hansen SF (2013) The European Union's chemical legislation needs revision. Nature Nanotechnology 8: 305-306.

87) DG Environment

DG

Environment.

Available:

http://ec.europa.eu/environment/pubs/pdf/factsheets/dg_environment.pdf. Accessed 27-042015.

88) DG Environment (2015) Environment DG Information Brochure http://ec.europa.eu/dgs/environment/pdf/information_brochure_en.pdf. Accessed 27-04-2015.

89) ECHA. 2013 The European Chemicals Agency. Available: http://echa.europa.eu/documents/10162/13556/echa_general_leaflet_en.pdf. Accessed 27-042015.

90) Wijen F, Zoeteman K, Pieters J, van Seters P (2012) A Handbook of Globalisation and Environmental Policy, Second Edition: National Government Interventions in a Global Arena. Edward Elgar Publishing

91) Aksoy D (2008) Member States' Success and Influence in European Union Policymaking. Dissertation. University of Rochester

92) Chemical Watch (2014) Sweden and Denmark's influence on EU policy, Global Business Briefing. Chemical Watch September 2014.

93) Prodi, Kinnock (2002) The Commission and Non-Governmental Organisations: Building a stronger partnership. Available: http://ec.europa.eu/transparency/civil_society/ngo/docs/communication_en.pdf. Accessed 2704-2015.

94) European Commission (2015) Non-governmental organisations. Available: http://ec.europa.eu/social/main.jsp?catId=330. Accessed 27-04-2015. 
95) European Commission (2015) LIFE (2014-2020). Available: http://ec.europa.eu/environment/life/funding/ngos/. Accessed 27-04-2015.

96) EEB 2015, http://www.eeb.org/index.cfm/about-eeb/the-eebs-mission/; $\quad$ EEB 2015, http://www.eeb.org/index.cfm/about-eeb/how-the-eeb-works/).

97) EEB (2015) About the EEB OUR DONORs. Available: http://www.eeb.org/index.cfm/abouteeb/our-donors/. Accessed 27-04-2015.

98) EEB (2015) Annual report 2013. Brussels: European Environment Bureau.

99) BEUC (2015) Financial Information. Available: http://www.beuc.org/about-beuc/financialinformation. Accessed 27-04-2015.

100) CIEL (2014) CIEL 2014 Annual Report. Geneva: CIEL.

101) CEFIC (2015) A short introduction to the European chemical industry. Available: http://www.cefic.org/Documents/About-Us/Short-Introduction-To-the-European-ChemicalIndustry-2014.pdf. Accessed 27-04-2015.

102) NIA (2015) Who we are. Available: http://www.nanotechia.org/about-nia. Accessed 27-042015.

103) NIA (2015) Our membership. Available: http://www.nanotechia.org/our-membership. Accessed 27-04-2015.

104) EMPF (2015) About the EPMF. Available: http://www.epmf.be/. Accessed 27-04-2015.

105) EMPF (2015) Members and partners. Available: http://www.epmf.be/index.php/menuepmf/members-and-partners. Accessed 27-04-2015.

106) SCHER, SCENIHR, SCCS (2013) Making Risk Assessment More Relevant for Risk Management the Scientific Committee on Consumer Safety (SCCS), the Scientific Committee on Health and Environmental Risks (SCHER) and the Scientific Committee on Emerging and Newly Identified Health Risks (SCENIHR). Brussels: European Commission 
107) Renn O, Webler T, Johnson BB (1991) Public participation in hazard management: the use of citizen panels in the US. Risk - Issues in Health and Safety 197: 197-226.

108) Glicken J (2000) Getting stakeholder participation 'right': a discussion of participatory processes and possible pitfalls. Environmental Science \& Policy 3: 305-310.

109) Freeman RE, Harrison JS, Wicks AC, Parmar BL, De Colle S (2010) Stakeholder Theory The State of the Art. Edinburgh: Cambridge University Press.

110) Svarstad H, Petersen LK, Rothman D, Siepel H, Wätzold F (2008) Discursive biases of the environmental research framework DPSIR. Land Use Policy 25: 116-125.

111) Syberg K, Hansen SF (2015) Environmental risk assessment of chemicals and nanomaterials The best foundation for regulatory decision-making? Science of the Total Environment 541: 784-794. 